\title{
LA HEROÍNA MODERNISTA (LA MUJER FINISE- CULAR EN LAS NOVELAS DE LLANAS AGUILANIEDO)
}

\author{
José Luis CALVO CARILLA \\ Universidad de Valladolid
}

José María Llanas Aguilaniedo fue autor de tres novelas y de la más temprana sistematización de la estética de la modernidad '. Su primera obra, Del jardín del amor, dedicada "a la clarísima memoria del crítico Leopoldo Alas (Clarín)", testimonia el magisterio ejercido por el ilustre escritor asturiano, quien en El Imparcial había saludado elogiosamente la Estética de Llanas Aguilaniedo $^{2}$. La influencia sobrepasa con creces la admiración y el respeto: deriva fundamentalmente del espíritu que inspira la gran novela clariniana y, en especial, del trazado de su personaje central, Ana Ozores, cuyas fibras interiores poseen una filigrana espiritual extremadamente moderna. De ahí que María de los Angeles Pacheco sea en cierto modo una réplica de Ana Ozores, asediada también como aquélla por un medio social adverso que, no obstante, en Del jardín del amor permanece en segundo plano, implícito y difuminado.

1. José $\mathrm{M}^{\mathrm{a}}$ Llanas Aguilaniedo (Fonz, Huesca, 1875-Huesca, 1921). Sus novelas son Del jardín del amor (1902), Navegar pintoresco (1903) y Pityusa (1908). En su reedición de esta última novela, Entrambasaguas (1955) ofrece un atinado estudio y una completa biografía. Un estudio reciente es el de Calvo Carilla, 1989, págs. 99-109.

2. Llanas Aguilaniedo, 1899. Esta deferencia del asturiano no excluye la valoración de J.M. Martínez Cachero (1983). El respeto de Llanas al maestro sólo se ve matizado por la observación de "novela taquiteléutica" que hace a La Regenta en su Alma Contemporánea. Estudio de Estética. (1899) (Calvo Carilla, 1987). El concepto de "novela taquiteléutica", con el que Llanas parece querer señalar una cierta precipitación o rapidez de factura en la confección de la obra, coincide con algunos reparos de la crítica contemporánea a Clarín y con lo que el propio autor abrigaba en su fuero interno. En carta a Jacinto Octavio Picón, fechada el 3-X-1885, escribía: "El defecto en que todos están conformes, o los más, es la pesadez, a lo largo de la obra y tienen razón. Si la hubiera escrito con más tiempo y con el borrador de lo escrito ya a la vista hubiera salido más corta, pero según iba escribiendo iba mandando el original y tenía que fiarlo todo a la memoria" (En Amorós, 1981, pág. 18). 
En la creación de estos dos grandes caracteres femeninos - y sin caer en las servidumbres del autobiografismo- debe señalarse también una cierta motivación autobiográfica común. Para Leopoldo Alas (1889, pág. 128), hay que amar a los personajes, transformarse en ellos y entrar en su interior. Lo que parte de la crítica contemporánea consideró proyección del espíritu de Clarín (Beser 1968; Tintoré 1987) puede aplicarse del mismo modo a Llanas Aguilaniedo, a la luz de la atormentada vida que, casi en la flor de la juventud, desembocó en la locura. Todos los personajes que pueblan sus novelas estarán dotados de una hipersensibilidad que limita con lo irracional.

Por otra parte, ambos novelistas construyen sus obras en torno al epicentro sísmico de un personaje (Beser, 1968, pág. 248). Para Clarín (1899, pág. 128), el novelista ha de crear almas. Su contemporáneo F. Heras lo presenta en 1895 como un psicólogo de la pasión, en términos muy parecidos a los que utiliza $\mathbf{J}$. Soler (Tintoré, págs. 238 y 251-252) para saludar la aparición de La Regenta. No otra cosa es Del jardín del amor que la historia de un alma torturada, la de María de los Angeles Pacheco, sumida en un "sáfico y platónico enamoramiento". Como la de Ana Ozores, su consistencia de heroína no es sólo fisiología ni sólo espíritu: es también un conjunto de deseos vagos, de aspiraciones más o menos trascendentes, incluso de sentimientos sin nombre (Lissorgues, 1987, pág. 21). Lo esencial humano en Ana, lo que trasciende al personaje y que, desde luego, es tanto de Clarín como puede serlo de cualquier hombre, es la búsqueda de una imposible unidad del ser, la aspiración a una plenitud que rebasa los límites tanto de la materia como del espíritu. Más allá del engaño de los sentidos, más allá de los extravíos románticos, más allá de la búsqueda mística equivocada (imitar el misticismo de Santa Teresa o de San Juan de la Cruz no es misticismo, las mediaciones, en tal caso, sólo desembocan en ilusiones) lo que busca Ana es algo que trascienda su existencia sin apoyo moral o afectivo (sin hijo), solitaria, escindida. Su vida desde la infancia hasta la caída es un camino de perfección, tan imperfecto como puede serlo la vida. Camino que se pierde, por afán de absoluto, en las nebulosas de la imaginación, que va, por desesperación, hacia las suertes de la locura...(Lissorgues, pág. 21).

Este diagnóstico puede servir para caracterizar a ambas heroínas. Las separa, en cambio, la mayor liberación de María de los Angeles Pacheco respecto a los postulados naturalistas. Si los ensueños y accesos místicos de Ana están en estrecha relación con la debilidad de su cuerpo y su exaltación interior obedece a los impulsos de un espíritu que, debido a su deficiente educación, no está bien dominado por la conciencia, en el caso de María de los Angeles se derivan de su condición de mujer superior, "hipermoderna", refinada espiritualmente en extremo. El punto de conflicto entre ambas lo señala de nuevo Lissorgues al hacer referencia a las concepciones un tanto puritanas del creador de La Regenta, para quien la conciencia debía ejercer siempre un papel 
vigilante, ya que, sin este manto protector, se llega al relajamiento del pensamiento y la voluntad, lo que lleva a Ana a una religión de los sentidos. El sensualismo religioso (y su consecuencia, el amoroso) son, para Alas, en el mejor de los casos, una impureza, algo demasiado ligado a la "quintaesencia" de los sentidos. Por otra parte, este sentir vuelto del todo sobre sí mismo es un sentir egoísta - mejor egotista- que puede hacer caer a quien lo experimenta en la atrevida impresión de que es un ser superior (Lissorgues, pág. 26).

Parecidas acusaciones habría podido lanzar el viejo maestro sobre la figura de María de los Angeles, heroína de una nueva época, aunque no tan distante de la factura de Ana, ya que la modernidad de esta última — puesta de relieve en varios estudios (Valis, 1983; Gullón, 1983; Sánchez, 1987)—, estriba en que sufre los condicionamientos de la novela naturalista, pero, a la vez, se escapa de ellos. Quizá porque Clarín concebía la novela como una "anatomía espiritual" que la hacía superior al teatro (Alas, 1892, pág. 297), había concedido a su personaje esa libertad que luego hará suya plenamente María de los Angeles Pacheco.

María de los Angeles encarna una de la modalidades de la heroína modernista. Si el héroe, que recoge la herencia romántica "genio", "mártir", "sacerdote" o "visionario" sin perder su dimensión aristocrática se enfrenta al mundo y pugna por definirse a sí mismo y concederse un programa de vida (Blasco Pascual, 1986, págs. 389-402), su correlato femenino también se nutre de perdurables esencias románticas. Su evolución a través del naturalismo - escuela a la que le interesa más lo fisiológico que lo psicológico-generará un tipo de mujer patológico y anómalo. Madame Bovary, Ana Karenina, Effi Briest y Ana Ozores, heroínas estudiadas por Biruté Ciplijauskaité, "sufren de los nervios": un sufrimiento que adquiere las proporciones de tristeza e incluso de locura al final (Ciplijauskaité, 1984, pág. 46). Carencias básicas que proceden en especial del "bovarysmo" más el "ozorismo" son la necesidad de afecto, dado y recibido y, en definitiva, su frustración como mujer (Mora, 1989, págs. 88 y ss.).

Esta herencia naturalista se prolongará en el fin de siglo favorecida por los avances científicos y la moda de la sociología criminal. Lily Litvak ha estudiado, a propósito de la contribución azoriniana, la influencia de estas corrientes en la creación literaria, desde novelas como La piedra angular de Emilia Pardo Bazán a La lucha por la vida de Baroja. La sociología criminal, supone, en cierto modo, reavivar los presupuestos naturalistas en cuanto a herencia y condicionamiento del medio y de la fisiología, que ayudan a explicar los casos degenerados o patológicos. No es ajeno a estos planteamiento Max Nordau, con sus aplicaciones al arte y a la literatura. Desde este "cientifismo" de las anomalías en las conductas no era difícil pasar al estudio de las enfermedades 
del alma o de la voluntad, punto en que confluyen las ciencias experimentales con las tendencias filosóficas antipositivistas ${ }^{3}$.

El fin de siglo presenta en la literatura y en las artes plásticas socorridos estereotipos de belleza femenina. Es la mujer ideal que se viste a la moda de París, con amplias ropas de tafetán o muselina, de cintura ajustada y guantes hasta el codo; que cubre su cabeza con grandes sombreros decorados con floridos jardines o variopintas cornucopias. El modern style destaca en ellas una nueva línea que realza su silueta, la amplía en evocadoras curvas y, en caso de necesidad, llega a enmendarla. Es la mujer ideal, encantadora, frívola, mundana, la musa de poetas, fotógrafos o príncipes rusos... (Waltzer, 1975, pág. 91).

Pero este modelo de belleza exterior coexiste con otro, cuyos encantos los proporciona la belleza espiritual de un alma inquietante, perversa, atormentada y misteriosa. Villiers de l'Isle Adam se había planteado la forma de complementar estas dos mujeres ideales. La Eva futura, surgida del laboratorio del "brujo" Thomas A. Edison constituye un revolucionario experimento de dotar de alma a una Alicia Clary afeada interiormente por un espíritu vulgar. La Hadaly que se reencarna en su espléndido cuerpo resulta una efímera ilusión que, pese a los desesperados esfuerzos de Lord Ewald, perece en el naufragio de todos los empeños irrealizables (De l'Isle Adam, 1885).

Los dos ideales de feminidad atraviesan el fin de siglo, pero es esa desconcertante complejidad psicológica la que ejerce un mayor poder de seducción. A menudo desdoblada en virgen y prostituta, en la Eva y en la María de los prerrafaelitas, la mujer es objeto de una atención cada vez más constante en la literatura, y en particular en las novelas, que, con frecuencia, tienen como título un nombre de mujer (Cerdá i Surroca, 1981).

En este protagonismo tiene mucho que ver los movimientos finiseculares de liberación de la mujer. En este sentido, la atención prestada por la Iglesia católica, que en 1854 proclama el dogma de la Inmaculada Concepción, es todo un síntoma del signo de los tiempos (Roldán Ruiz y Valenzuela Jiménez, 1987, pág. 442; Freixa, 1984, págs. 119-138), cuando no un intento de apropiación religiosa de la naciente "cuestión de la mujer". Aunque en España tienen lugar

3. Fundada por el médico italiano Cesare Lombroso, la sociología criminal tuvo una gran repercusión en Europa durante el último cuarto del siglo XIX. Sus aportaciones, destinadas inicialmente a estudiar los comportamientos marginales de la sociedad, tuvieron, en discípulos como Ferri, una aplicación al derecho penal, a la medicina, a los sistemas penitenciarios, a la sociología, a la psicología, etc. y, en general, afectó, en mayor o en menor medida, a todos los intelectuales del fin de siglo, con actitudes de aceptación o de rechazo fuertemente encontradas. Como estudia L. Litvak (1990, págs. 129-154), Llanas Aguilaniedo se cuenta entre los muchos seguidores de Lombroso en España, con estudios específicos como La mala vida en Madrid. Estudio psicofisiológico o su traducción de La mala vida en Roma. Sobre la influencia de Max Nordau, frecuentemente asociada a la de Lombroso y su relación con la estética de Llanas se han ocupado en fechas recientes J.C. Mainer, 1989 y J.L. Calvo Carilla, 1991. 
con un cierto retraso histórico, escritoras como Concepción Arenal, Emilia Pardo Bazán o Carmen de Burgos denuncian desde distintas posiciones la postergación social y exigen igualdad de derechos con el hombre. Tampoco son ajenos a estas corrientes los principios de la filosofía krausista, respetuosa con su dignidad e impulsora de la coeducación y preparación para otros oficios diferentes de la enseñanza. En estos momentos cruciales para la historia del feminismo, Llanas — que llegó a simpatizar con el krausismo, como lo demuestran sus colaboraciones en la Revista de la Institución Libre de Enseñanza (Llanas Aguilaniedo, 1902b y 1903b; Esteban Mateo, 1978)—, es sensible a algunos de sus planteamientos. Como concluye su artículo "La Eva futura":

la mujer por su parte mirará cada vez con menos simpatía a un orgulloso - cuando no un tirano - que aprovecha cuantas ocasiones se le presentan para humillarla, tratándola desdeñosamente desde lo alto de su torre dorada, y en el cual tampoco hallará interés, pues ni el talento y erudición, ni otras prerrogativas de la masculina raza, satisfarán jamás a la mujer como un poco del sentimiento de la vida que ella perpetúa y conserva. (Llanas Aguilaniedo, 1901, pág. 7)

María de los Angeles Pacheco ejemplifica este modelo finisecular de mujer libre e intelectualmente superior. En su espíritu brillan los destellos del superhombre nietzscheano. Si bien las ideas de Nietzsche sobre la emancipación de la mujer ilustran la actitud negativa general en su tiempo, con poco esfuerzo podrían espigarse - por ejemplo, del capítulo VII del El viajero y su sombra, aunque con reservas relativas a las capacidades y complejidad del carácter femenino ${ }^{4}$ - opiniones más favorables. Con todo, no es difícil que, en su consideración genérica, la bandera del "hombre superior" arrope también a la mujer, a la que el propio Nietzsche considera como un cerebro lúcido, complejo y ansioso de superación. La recepción de Nietzsche en España —que Gonzalo Sobejano ha documentado a partir de 1893 - , confluye con la de otros grandes maestros del momento (Maeterlink, Ibsen, etc). Por muy diferentes que sean sus creaciones, apunta en ellos como rasgo coincidente el trazado de unos caracteres que sobresalen de la vulgaridad colectiva. La Nora ibseniana es una de las máximas realizaciones de este aristocratismo irrepetible, encarnado con valor añadido y ejemplar en un personaje femenino.

Alma contemporánea. Estudio de estética (1989) es uno de los testimonios más tempranos de la presencia de Nietzsche en España (Sobejano, 1967, págs. 65-66). La lectura que del autor de Así habló Zaratustra realiza el oscense sigue en líneas generales la mediación hermenéutica que Joan Maragall y Pompeyo

4. En Nietzsche (1985, págs. 2081-2096). Del testimonio de Leopoldo Alas (1899) — cuyas ideas al respecto, dentro de su comprensiva moderación, pretenden quitar hierro frente a los detractores del alemán-, se desprende, no obstante, que las ideas de Nietzsche sobre la mujer fueron interpretadas en la época como totalmente negativas. 
Gener habían realizado en sus fragmentarias traducciones de Així va parlar Zarathustra. Frente a los "castellanos", que pusieron el énfasis en el disolvente anarquismo del filósofo, los catalanes se fijan en el "hombre superior", aristócrata de alma y de cuerpo frente a los débiles y decadentes (Sobejano, 1967, págs. 38-40).

Profundamente nietzscheana es María de los Angeles Pacheco. El medio, lejos de determinar su comportamiento, es solamente un degradado marco de contraste frente al que surge el torrente emocional al margen de normas y convenciones. Su diario es la crónica de un amor físico e intelectual que, de acuerdo con Felipe Trigo, si se desarrollase en libertad podría llegar a una Armonía completa ${ }^{5}$.

Es el aristocratismo de un ser superior y de sus selectas manifestaciones espirituales que cobra vida literaria en los personajes dannunzianos.

Gabrielle D'Annunzio goza de gran popularidad en la España finisecular. Todos los testimonios recogidos por Sobejano reflejan la consideración del italiano como discípulo y difusor de Nietzsche, ya que su esteticismo se interpretaba como la versión artística de la ecuación nietzscheana vida-fuerza ${ }^{6}$. Como ha estudiado Bugliani, la presencia de D'Annunzio es muy compleja y difusa. Entre sus diversas manifestaciones, que van desde lo superficial a lo satánico, el modernismo peninsular muestra predilección por un esteticismo cerebral, un refinamiento en el lenguaje y un aristocrático desprecio por todos los aspectos de la vida corriente, por los principios y los ideales tradicionales ? El refinamiento, la neurosis, la voluptuosidad espiritual de los seres que pueblan obras como la influyente Città morta contaminan las páginas de muchas novelas contemporáneas.

5. Al menos esa es la tesis que excepcionalmente se cumple en su novela Las Evas del Paraíso (1910). La cosmovisión novelesca del pacense Felipe Trigo (1864-1916) - que debió coincidir en alguna ocasión con Llanas, ya que era médico militar-, tiene algunos puntos en común con éste en cuanto al tratamiento del amor intelectual y sensual, místico y humano, aunque sus personajes de mayor interés sean los masculinos. Expuso sus ideas en la conferencia de $1907 \mathrm{El}$ amor en la vida y en los libros, ampliada y editada más tarde como El amor en la Vida y en los libros. Mi ética y mi estética. De este autor se ocupan L. Litvak (1979) y A. Martínez San Martín (1983).

6. Sobejano (1967, pág. 214) recoge de testimonios contemporáneos la consideración de D'Annunzio como intermediario entre Nietzsche y Valle Inclán y la interpretación de su esteticismo como versión artística de la ecuación nietzscheana vida-fuerza.

7. Bugliani (1976, pág. 11) escribe a este respecto: “L'umanitarismo democratico viene sostituito con un dividualismo aristocraticamente autonomo che nella contemplazione dei misteri della vita e degli enigmi del mondo spesso assume aspetti mistici la cui comprensione e privilegio esclusivo di pochi individui seletti. Da questo modo di vedere la realtà della vita scompare l'assoggettamento al tempo fisico presente, e sorge una nuova poetica formata con un tempo psichico e questo a sua volta composto di elementi puramente musicali che servono di complemento per la conoscenza dell' anima". 
María de los Angeles es de las mujeres que, como la Madame Roche de $L a$ ciudad en la niebla, dividen a la humanidad en dos partes: la constituida por bellas señoras intelectuales y hombres de talento y la de la gente vulgar y ordinaria.

Quizás sea en Pityusa (Llanas Aguilaniedo, 1908) donde se dan cita todas las características del italiano: el paganismo de una naturaleza salvaje, la posesión y el dominio hasta el sadismo o una moral que abarca desde la inocencia hasta la perversión. A la altura de 1908, D'Annunzio se ha convertido en una obsesión para los personajes de Llanas Aguilaniedo, hasta el punto de que hace pensar a Pityusa:

¡Cómo y dónde se hallaría D’Annunzio!

Sin duda viviendo la existencia de luz que reflejaba en las pomposas páginas. Antiguas ciudades, radiantes aún con la ceniza de riquezas pretéritas; monumentos, tesoros de arte acumulados por la labor de las generaciones; cuanto bello y heroico había entrevisto al estímulo de aquella genialidad fastuosa y desbordante, volaba en su cerebro, inflamándole las sienes, haciendo correr y serpear por sus venas fuego líquido.

¡Oh, sí! Era aquélla su musa, su inspiración, el genio amigo. Convencería a su hombre, escribiría ella también; la incomparable esencia hormigueaba y se difundía bajo su frente. ¡A cualquier precio sentirla, sufrir y gozar con sus amores, quemarse en su llama con la sublime inspiración del que juega a conciencia su vida en cada instante! (Llanas Aguilaniedo, 1908, pág. 260).

Pero ya en Del jardín del amor: las dos citas danunzianas demuestran sin lugar a dudas la admiración de Llanas hacia la complejidad espiritual de las criaturas del escritor italiano, lo que se materializará en el sensible y voluptuoso perfil anímico de María de los Angeles Pacheco.

Y si D’Annunzio es uno de los artífices de la ampliación de los confines del alma, diversas incitaciones finiseculares confluyen en la exploración de las fronteras racionales de los personajes. Un arte de sugerencias, como el modernista, que fluye del sentimiento y de la emoción y que está orientado a ser aprehendido por la intuición, era un arte que se oponía a la razón y que abría un resquicio para que aflorara el subconsciente del autor y para que se conmocionara el subconsciente del lector. Si bien los trabajos de Freud no debieron de ser conocidos todavía en España cuando Llanas Aguilaniedo escribía Del jardín del amor, existía una corriente con precedentes autóctonos en este tipo de indagaciones, representada por críticos y novelistas como Urbano González Serrano, Eduardo Gómez de Baquero o el mismo Pío Baroja (Celma Valero, 1989, pág. 143 y ss.). De su progresiva incorporación a la creación novelesca pueden encontrarse ejemplos en Del jardín del amor, Camino de perfección (Baroja, 1902) o en Amor y pedagogía (Unamuno, 1902). 
En el fondo, estos escarceos responden a algo que está en el ambiente finisecular y que obedece en última instancia, —como ha señalado Tadié-, a las pretensiones científicas de la psicología, cuyo influjo irá modulando la dislocación exterior e interior del héroe, ya que ella constituye el horizonte ideológico de los novelistas y nutre el aire que respiran. Cuando, según Taine y los ingleses el yo no es más que una serie de estados de conciencia, cuando la Psicologie de l'inconscient de Hartmann se ha traducido (al francés, en 1877), cuando Ribot estudia sucesivamente las enfermedades de la memoria, de la voluntad, de la personalidad, se observa cómo se constituye una nueva cultura, que será común a Freud, a Bourget, a Proust, en el que se encuentran las etapas de la degradación del positivismo (Tadié, 1978, pág. 14).

De todos estos estímulos vivificadores surge esta mujer excepcional de Llanas Aguilaniedo. Como más tarde Pityusa, María de los Angeles Pacheco se convierte en una de las heroínas más emblemáticas del fin de siglo. Puesta en pie inicialmente con la convicción humana que puede proporcionar un caso clínico, su creador hace suyas las aspiraciones de J.K. Huysmans en boca de su personaje Durtal, cuando decía que "es necesario conservar la veracidad del documento, la precisión del detalle, el lenguaje fastuoso y nervioso del realismo; pero también es necesario hacerse buzo de almas y no pretender explicar el misterio por las enfermedades de los sentidos. Si se pudiera, la novela debería dividirse por sí sola en dos partes, la del alma y la del cuerpo, soldadas o más bien confundidas como lo están en la vida, y ocuparse de sus reactivos, de sus conflictos y de su unión. En una palabra, sería necesario seguir la ancha vía abierta tan profundamente por Zola; pero también se necesitaría trazar en el aire un camino paralelo, otra ruta, uniendo las dos, creando, finalmente, un naturalismo espiritualista. ¡Eso sí que sería lo hermoso, lo completo, lo fuerte!". Para concluir que "por el momento, no lo hace nadie. A lo más, podría citarse, como aproximándose a ese concepto a Dostoievski” (Huysmans, 1891, pág. 15).

Aspiración que se materializa en María de los Angeles, sensualidad y espíritu, grandioso estudio de una pasión encarnada en un ser escogido que se independiza de su creador $y$, al margen de restricciones narrativas o morales, vive y se muestra en su jardín con la franqueza, el ardor y aun la altivez de todo ser humano que siente vocación para ello y ocupa en la sociedad un puesto libremente elegido. Del mismo modo que la cortesana Afrodita, tendrá la ambición de elevarse al más alto lugar y ni siquiera imaginará que su vida tenga necesidad de excusa o de misterio (Louÿs, 1885, pág. 27).

En alguna ocasión han sido relacionadas las criaturas de Llanas con las de este raro escritor francés (González Blanco, 1909, pág. 1000), con quien sin duda comulga en el erotismo y la voluptuosidad que destilan sus novelas y en el 
relieve que alcanzan sus heroínas. (Sin olvidar las Canciones de Bilitis, que conforman ya "una a modo de novela lírica en cuyo curso se desarrolla y se exalta el amor lesbiano más poderoso y vehemente que el amor normal, la voluptuosidad entre mujeres que glorificó Safo y que en nuestros tiempos han cantado Baudelaire, Verlaine y varias poetisas desfallecientes bajo la crueldad encantadora de su pasión anormal"-Blasco Ibáñez, en Louÿs, 1885, pág. 15). Pero los paralelismos terminan allí donde emerge la complejidad de la heroína de Llanas, superior al pagano refinamiento de Afrodita o la enigmática perversión, casi rayana en el sadismo de la sevillana Conchita (Louÿs, 1898), carentes ambas de la dimensión espiritual que caracteriza a María de los Angeles Pacheco. Dicha complejidad y la intensidad con que experimenta sus emociones, a expensas de cualquier intento de novelación decimonónica, confieren a esta obra la plenitud en la plasmación de la anatomía de un alma. Pierre Louÿs enriquecido con las cargas de profundidad de D'Annunzio. Porque $\mathbf{M}^{\mathrm{a}}$ de los Angeles es, como las criaturas dannunzianas, mítica habitante de una ciudad muerta, única superviviente de un paraíso cuyas inagotables bellezas no tienen otro contemplador que quien las cultiva.

\section{BIBLIOGRAFIA}

ALAS, Leopoldo. 1889. Mezclilla. Madrid, Enrique Rubiños.

-. 1899. "Nietzsche y las mujeres". El Español, 6 y 7-IX.

En RAMOS GASCÓN, A. (Ed.). Clarín. Obra olvidada. Madrid, Júcar, 1973, págs. 199-209.

- 1892. Ensayos y Revistas. Madrid, M. Fernández y Lasenta.

AMORÓS, Andrés. 1981. "Doce cartas inéditas de Clarín a Jacinto Octavio Picón". Los Cuadernos del Norte, II, 7, págs. 8-20.

BAROJA, Pío. 1902. Camino de perfección. Reedición: Madrid, Caro Raggio, 1974.

BESER, Sergio. 1968. Leopoldo Alas, crítico literario. Madrid, Gredos.

BLASCO PASCUAL, Francisco Javier. 1986. "Algunas notas para el estudio de la presencia de Gracián en el 'héroe' modernista". Actas de la I Reunión de filólogos aragoneses. Zaragoza, Institución Fernando el Católico, págs. 389-402.

BUGLIANI, Americo. 1976. La presenza di D'Annunzio in Valle-Inclán, Milano, Cisalpino-Goliardica.

CALVO CARILLA, José Luis. 1987. "Clarín y Aragón (Dos notas bibliográficas)". En Hitos y Mitos de La Regenta. Monografías de Los Cuadernos del Norte, 4, págs. 132-133.

- 1989. "La solitaria aventura de Llanas Aguilaniedo". En El modernismo literario en Aragón. Zaragoza, Institución Fernando el Católico, págs. 99-109.

—. 1991. "Alma contemporánea: una estética de la modernidad". Castilla, 15, págs. 33-51. 
CELMA VALERO, Mํㅗ. Pilar. 1989. La pluma ante el espejo. Salamanca, Universidad.

CERDÁ I SURROCA, Mํa Angela. 1981. Els pre-rafaelites a Catalunya. Una literatura $i$ uns simbols. Barcelona, Curial.

CIPLIJAUSKAITÉ, Biruté. 1984. La mujer insatisfecha. El adulterio en la novela realista. Barcelona, Edhasa.

ENTRAMBASAGUAS, Joaquín. 1955. Las mejores novelas contemporáneas. Barcelona, Planeta, vol. III.

ESTEBAN MATEO, Luis. 1978. Boletín de la Institución Libre de Enseñanza. Nómina Bibliográfica (1877-1936). Valencia, Universidad.

FREIXA SERRA, Mireia. 1984. "La imagen de la mujer en el modernismo catalán". La imagen de la mujer en el arte español. Madrid, Universidad Autónoma, págs. 119-138.

GONZÁLEZ BLANCO, Andrés, 1909. Historia de la novela en España desde el Romanticismo a nuestros días. Madrid, Sáenz de Jubera Hnos. Editores.

HERAS, Fernando. 1895. "Don Leopoldo Alas Clarín". La Vanguardia, 12-VI. En TINTORÉ, Mà José. La Regenta de Clarín y la crítica de su tiempo. Barcelona, Lumen, 1987, págs. 232-241.

HUYSMANS, Joris-Karl. 1891. Là-bas. Traducción de G. GOMEZ DE LA MATA: Allá lejos. Barcelona, Bruguera, 1986.

LISSORGUES, Yvan. 1987. "Ética, religión y sentido de lo humano en La Regenta". Hitos y mitos de La Regenta, cit., págs. 20-31.

LITVAK, Lily. 1979. Erotismo fin de siglo. Barcelona, Bosch.

- 1990. "La sociología criminal y su influencia en los escritores españoles de fin de siglo". En España 1900. Modernismo, anarquismo y fin de siglo. Madrid, Anthropos, págs. 129-154.

LOUYS, Piere. 1885. Aphrodite. Versión española de J. MARTINEZ CLAVEL: Afrodita. Prólogo de Vicente BLASCO IBAÑEZ, Valencia, Prometeo, s.a.

- 1898. La Femme et le Pantin. Traducción de Emiliano RAMIREZ ANGEL: La mujer y el muñeco. Prólogo de V. BLASCO IBAÑEZ, Valencia, Prometeo, s.a.

LLANAS AGUILANIEDO, José Mª 1989. Alma Contemporánea. Estudio de Estética. Huesca, Tip. de Leandro Pérez.

-. 1901. "La Eva futura". Juventud, 1, pág. 7.

- 1902a. Del jardín del amor. Madrid, Libr. de Fernando Fe - Libr. de Victoriano Suárez.

—. 1902b. "El obrero y la taberna". Boletín de la Institución Libre de Enseñanza, XXVII, págs. 115-122.

- 1903a. Navegar pintoresco. Madrid, Libr. de Fernando Fe - Libr. de Victoriano Suárez.

—.1903b. "Trabajo y Zola", Boletín de la Institución Libre de Enseñanza, XXVIII, págs. 123-128.

—. 1908. Pityusa. Madrid, Fernando Fe. 
MAINER, José-Carlos. 1989. "La crisis de fin de siglo a la luz del "emotivismo": sobre Alma Contemporánea (1899) de Llanas Aguilaniedo". En Letras aragonesas. Zaragoza, Oroel, págs. 97-115.

MARTÍNEZ CACHERO, José M"a. 1983. "Sobre la actitud antimodernista del crítico Clarín". Anales de Literatura Española, 2, págs. 383-398.

MARTÍNEZ SAN MARTÍN, Antonio. 1983. La narrativa de Felipe Trigo. Madrid, C.S.I.C.

MORA, Magdalena. 1989. "La construcción de la identidad en el personaje novelístico. Madame Bovary (1837) y La Regenta (1884-1885)". En Teoría del personaje (Compilación de Carlos CASTILLA DEL PINO). Madrid, Alianza Universidad, págs. 75-97.

NIETZSCHE, Frederich. 1985. Obras Completas. Traducción de E. EIDELSTEIN, M.A. GARRIDO Y C. PALAZÓN. Barcelona, Teorema, 4 vols.

ROLDÁN RUIZ, Amalia; VALENZUELA JIMÉNEZ, Rafaela. 1987. "La mujer finisecular en la obra de Manuel Reina". Actas del Congreso Internacional sobre el modernismo español e hispanoamericano. Ed. de Guillermo CARNERO. Córdoba, Diputación, págs. 441-445.

SANCHEZ, Elizabeth. 1987. "Más allá del paradigma realista: estratagemas subversivas en La Regenta y Madame Bovary”. Hitos y Mitos de La Regenta, cit., págs. 63-67.

SOBEJANO, Gonzalo. 1967. Nietzsche en España. Madrid, Gredos.

SOLER, Josep. 1895. "Clarín”, La Publicidad, 15-VI. (En TINTORE, María José., op. cit., págs. 242-252).

TADIE, Jean-Yves. 1978. Le récit lyrique. Paris, Presses Universitaires de France.

TINTORE, María José. 1987. La Regenta de Clarín y la crítica de su tiempo. Barcelona, Lumen.

TRIGO, Felipe. 1910. La Evas del Paraíso. Madrid, Renacimiento.

-.1920. El amor en la vida y en los libros. Mi ética y mi estética, Madrid, Renacimiento. ( $\left.5^{\frac{a}{2}}\right)$.

UNAMUNO, Miguel de. 1902. Amor y pedagogía. Reedición: Madrid, Alianza, 1989.

VALIS, Noël. 1983. "Order and Meaning in Clarín's La Regenta", Novel, 16, págs. 246-258.

VILLIERS de l'ISLE ADAM, Jean-Marie. 1885. La Eva Futura. Trad. de Mauricio BACARISSE. Madrid, Valdemar, 1988.

WALTZER, Pierre-Olivier. 1975. Le XXe. siècle, I 1896-1920. Paris, Arthaud. 